\title{
EKSISTENSI SUFISME DALAM TRADISI PEDAQ API DI LOMBOK
}

\author{
Nur Azizah Zuhriah ${ }^{1}$, Warto $^{2}$, Titis Srimuda Pitana ${ }^{3}$ \\ Program Studi S-2 Kajian Budaya, Fakultas Pascasarjana, Universitas Sebelas Maret Surakarta, \\ Surakarta, Indonesia ${ }^{123}$ \\ zuhriahazizah@gmail.com ${ }^{1 *}$
}

\begin{abstract}
This study discusses the existence of Sufism in the tradition of the pedaq api in Lombok. Pedaq api as a naming procession cannot be interpreted visually, but is a 'text' culture that is full of meaning and represented by symbolic signs. The elements that exist in the pedaq api imply the essence of the human self itself, because it is motivated by philosophical thinking that interprets the elements of human life. The analysis used is the semiotic Roland Barthes methodology. From this study three concepts of the existence of sufism were obtained in the tradition of the pedaq api. First, the tradition of pedaq api as salvation. Second, the tradition of the pedaq api as an intermediary to remind the agreement of the child with his God. Third, the tradition of pedaq api as a representation of the journey of human life from the beginning of the incident to death.
\end{abstract}

Keywords: existence; sufism; pedaq api

\begin{abstract}
Abstrak
Penelitian ini bertujuan membahas unsur eksistensi sufisme yang terdapat dalam tradisi pedaq api di Lombok. Pedaq api sebagai prosesi pemberian nama tidak dapat dimaknai secara visual, melainkan merupakan suatu 'teks' budaya yang sarat makna dan direpresentasikan melalui tanda-tanda simbolik. Unsur-unsur yang ada pada pedaq api menyiratkan esensi dari diri manusia itu sendiri, karena dilatarbelakangi oleh pemikiran filosofis yang menginterpretasikan unsur-unsur kehidupan manusia. Sumber data adalah data primer dan data sekunder. Data primer menjadi data utama dalam bentuk tidak tertulis berupa kata-kata, tindakan, ungkapan, dan peristiwa yang terjadi dalam konteks tradisi pedaq api. Data primer diperoleh dari pengamatan langsung terhadap simbolisasi pedaq api dan wawancara dengan informan-informan terpilih yang dicatat melalui catatan tertulis, perekaman suara, dan/atau pengambilan gambar melalui kamera. Data sekunder sebagai data terulis berupa buku-buku, media cetak, jurnal-jurnal, dokumen-dokumen, dan hasil-hasil penelitian terdahulu yang terkait dengan tradisi pedaq api. data tertulis ini diperoleh dari studi dokumen dan studi kepustakaan. Analisis yang digunakan adalah metodologi semotika Roland Barthes yakni dengan cara menemukan makna denotatif, makna konotatif, dan mitos simbolik dalam tradisi pedaq api. Hasil penelitian ditemukan tiga konsep eksistensi sufisme dalam tradisi pedaq api. Pertama, tradisi pedaq api sebagai keselamatan. Kedua, tradisi pedaq api sebagai perantara untuk mengingatkan perjanjian anak dengan Tuhannya. Ketiga, tradisi pedaq api sebagai representasi dari perjalanan hidup manusia dari awal kejadian sampai kematian.
\end{abstract}

Kata kunci: eksistensi; sufisme; pedaq api

\section{Pendahuluan}

Pedaq api merupakan rangkaian upacara dalam tradisi pemberian nama pada anak di Lombok. Upacara ini dilaksanakan setelah tujuh sampai sembilan hari usia bayi yang ditandai dengan terputusnya tali pusar. Pedaq api dilaksanakan sebagai bentuk ungkapan syukur kepada Allah SWT atas anugerah kehidupan yang diterima. Oleh karenanya, suatu pemberian dari Yang Mahakuasa harus disyukuri serta dimuliakan dengan mengadakan ritual, dan salah satunya adalah ritual pedaq api. Dalam hal ini, ritual sebagai simbol kultural pada dasarnya merupakan cara berkomunikasi secara simbolik dengan sesama pengkosmos 
yang ada di alam ini melalui penyerahan diri kepada Tuhan Yang Mahakuasa (Fathurrahman, 2017: 36; 151).

Tradisi pedaq api sebagai bagian dari upacara kelahiran anak memiliki arti secara filosofis, religi, dan sosial. Pedaq api secara filosofis merupakan salah satu bagian dari cara memuliakan kehidupan. Bagi masyarakat Sasak, hidup dipandang sebagai paice (anugerah) yang bersumber dari Yang Maha Hidup. Sebagai anugerah hidup harus dimuliakan dan dijalani dengan rasa syukur. Salah satu caranya adalah dengan melaksanakan ritual sebagai bentuk rasa syukur menerima paice (Fathurrahman, 2017: 144). Begitu juga dengan pedaq api sebagai bentuk rasa syukur atas paice yang diterima, yaitu memiliki seorang anak.

Secara religi, tradisi pedaq api sebagai cara memuliakan kehidupan memandang bahwa seluruh kehidupan makhluk, meliputi kehidupan benda materi (nabbani), kehidupan tumbuhan (nabati), kehidupan binatanag (hewani) dan kehidupan manusia (insani) di seluruh jagat berasal dari Allah SWT. Pengetahuan dan kesadaran tentang kehidupan ini merupakan pengetahuan yang wajib dituntut, jika tidak maka kehidupan seseorang sama halnya dengan kehidupan hewan (Fathurrahman, 2017: 140). Secara sosial, tradisi pedaq api merupakan perantara dalam mengingatkan perjanjian manusia dengan Tuhannya. Sebagaimana manusia hidup di alam, keseluruhan peradaban pada dasarnya merupakan upaya untuk mememelihara keseimbangan kosmologis sebagai salah satu bagian dari tugas dalam melaksanakan kekhalifahan di bumi. Upaya memelihara dan menyelaraskan hubungan dengan alam diekspresikan dengan ritual dalam rangka memelihara dan saling menghargai (Eller, 2007: 112; Fathurrahman, 2017: 27).

Nilai-nilai yang ada dalam tradisi tradisi pedaq api berperan penting dalam kehidupan manusia terutama bagi masyarakat Sasak Lombok sebagai pelaku tradisi. Bahkan, nilai-nilai yang ada menunjukkan adanya eksistensi sufisme yang melekat dalam tradisi pedaq api, namun tidak banyak yang mengetahuinya.

Eksistensi sufisme mengacu pada kosmologi masyarakat Sasak yang berpangkal pada sikap tauhid, yaitu kesadaran tentang keberadaan Zat yang menjadi sumber dan tempat kembalinya segala kehidupan (Fathurrahman, 2017: 24). Oleh karenanya, segenap aktivitas masyarakat Sasak secara universal disandarkan pada aspek ketauhidan termasuk sikap-sikap kultural yang sudah lama menjadi tradisi (Maryam, 2018: 34). Dalam realitasnya, masyarakat terutama generasi muda memposisikan diri sebagai generasi yang maju, tidak lagi percaya dengan hal-hal yang bersifat metafisika karena memiliki perspektifnya masingmasing dalam memandang suatu realitas. Akibatnya, nilai-nilai penting yang ada dalam tradisi pedaq api sering diabaikan dan mengaburkan makna yang ada di baliknya. Oleh karena itu, perlu adanya tindakan cerdas dalam upaya meningkatkan pemahaman masyarakat tentang eksistensi makna yang ada dalam tradisi pedaq api. Untuk itu, penelitian ini bertujuan untuk mengetahui eksistensi sufisme yang direpresentasikan melalui simbol-simbol yang ada dalam tradisi pedaq api di Lombok.

Kajian tentang tradisi pedaq api sebelumnya dilakukan oleh Suhardi, dkk (2010) dalam buku yang berjudul Upacara Daur Hidup Suku Sasak. Dalam penelitian ini dijelaskan ada tiga acara penting yang berkaitann dengan kelahiran, yaitu (1) tukak ariq kakaq; (2) peraq api; (3) ngurisang dan besunat. Upacara peraq api dijelaskan sebagai rangkaian 


\section{e-ISSN 1412-9418 \\ Humanika Vol. 26 no 2 Copyright @2019 \\ Available online di http://ejournal.undip.ac.id/index.php/humanika}

upacara yang diadakan sehubungan dengan adanya kelahiran anak. Suhupawati (2015) menjelaskan bahwa dalam proses ritual kelahiran memiliki dua fungsi, yaitu fungsi spiritual dan fungsi sosial dalam pelaksanaannya. Berdasarkan fungsi dari upacara adat kelahiran ini timbul nilai-nilai kearifan adat yakni nilai keagamaan, nilai gotong royong, nilai solidaritas, cinta tanah air, nilai kepemimpinan, dan nilai tanggung jawab.

Ansori (2018) menyatakan bahwa dinamika perubahan yang terjadi pada masyarakat Kawo dalam tradisi peraq api diklasifikasikan kedalam dua faktor, yakni faktor internal dan faktor eksternal. Faktor internal terjadi karena putusnya generasi dan cara pandang masyrakatnya. Faktor eksternal terjadi karena Keterbukaan Informasi, munculnya anasir pemahaman moderen dan kemajuan literasi masyarakat. Zulkarnaen (2019) menunjukkan nilai-nilai Pancasila dalam ritual pedak api, yaitu (1) Nilai Ketuhanan Yang Maha Esa yaitu gelang yang terbuat dari benang hitam putih, sembekan, do'a danzikiran; (2) Nilai Kemanusiaan Yang Adil dan Beradab terdapat pada apus tawar, melulurkan, mengayunkan bayi, dan pemberian nama; (3) Nilai Persatuan Indonesia terdapat pada mengundang masyarakat dan tokoh agama; (4) Kerakyatan Yang Dipimpin Oleh Hikmat

Kebijaksanaan Dalam Permusyawaratan/ Perwakilan terdapat pada pemberian nama; (5) Keadilan Sosial Bagi Seluruh Rakyat Indonesia terdapat pada makan bersama.

Dari keseluruhan penelitian terdahulu tentang tradisi pedaq api dapat dicatat dua hal penting. Pertama, kajian-kajian tersebut tidak menunjukkan makna simbolik yang ada dalam tradisi pedaq api secara spesifik. Kedua, kajian-kajian tersebut tidak ditampakkan interpretasi terhadap makna simbol-simbol yang ada dalam pedaq api. Ketiga, kajian-kajian tersebut memiliki kesamaan dalam memposisikan tradisi pedaq api sebagai bagian dari upacara pemberian nama pada anak. Peneilitain ini lebih spesifik membahas makna simbol yang ada dalam tradisi pedaq api. Analisis yang digunakan adalah semiotika Roland Barthes.

Dalam memaknai pedaq api, tidak cukup dengan menemukan makna denotatif dan konotatifnya, melainkan ada makna tersembunyi yang disebut oleh Barthes sebagai kawasan ideologi atau mitologi, dimana mitos merupakan cara untuk mengonseptualisasikan atau cara memahami sesuatu (Sobur dalam Rahmawati, dkk. 2017:77). Mitos sebagai suatu ideologi untuk memahami realitas berfungsi sebagai proses memahami makna pedaq api. Segala jenis unsur-unsur dalam ritual pedaq api meliputi bahasa, simbol, dan objek merupakan suatu tanda yang dapat ditelususri maknanya melalui konotatif penanda untuk menemukan makna-makna tersembunyi di balik realitas suatu tanda. Masalah penelitian yang dirumuskan adalah bagaimanakah makna simbolik tradisi pedaq api yang merepresentasikan adanya unsur sufistik dalam prakteknya di Lombok.

\section{Metode Penelitian}

Metode penelitian yang digunakan adalah metode kualitatif. Penelitian kualitatif tidak semata-mata mendeskripsikan, tetapi yang lebih penting adalah menemukan makna yang terkandung di baliknya, sebagai makna tersembunyi, atau dengan disembunyikan. Secara umum, penelitian kualitatif didefinisikan sebagai penenelitian yang menggunakan analisis data deskriptif berupa kata-kata dan/atau ungkapan-ungkapan, termasuk di dalamnya 


\section{e-ISSN 1412-9418 \\ Humanika Vol. 26 no 2 Copyright @2019 \\ Available online di http://ejournal.undip.ac.id/index.php/humanika}

tindakan-tindakan yang dapat diamati dalam tradisi pedaq api (Pitana, 2014: 21). Dengan demikian kualitatif adalah metode yang menghasilkan data deskriptif dalam bentuk katakata, baik tertulis maupun lisan (Ratna, 2016: 94). Sumber data dalam penelitian ini adalah data tentang makna simbolik tradisi pedaq api yang ditampilkan dalam bentuk naratif dan bersifat kualitatif dan terdiri atas dua sumber data. Pertama, sumber tidak tertulis berupa kata-kata, tindakan, ungkapan, dan peristiwa yang terjadi dalam konteks tradisi pedaq api. Dalam hal ini digunakan sebagai sumber data utama (primer). Sumber data utama diperoleh dari pengamatan langsung terhadap simbolisasi pedaq api dan wawancara dengan informan-informan terpilih yang dicatat melalui catatan tertulis, perekaman suara, dan/atau pengambilan gambar melalui kamera.

Kedua, sumber data terulis berupa buku-buku, media cetak, jurnal-jurnal, dokumendokumen, dan hasil-hasil penelitian terdahulu yang terkait dengan tradisi pedaq api dan maknanya dalam hal ini digunakan sebagai sumber data sekunder. Sumber data tertulis ini diperoleh dari studi dokumen dan studi kepustakaan.

Untuk menemukan makna tanda dalam pedaq api termasuk hal-hal tersembunyi di balik tanda, pendekatan yang digunakan dalam penelitian ini adalah semiotika Roland Bartes, dimana analisis pertandaan Barthes mencakup makna denotatif, konotatif, dan mitos. Barthes mengesplorasi mitos sebagai sistem pertandaan kedua 'secondary signification' yang berada dalam makna konotatif dari gambar atau 'sign' yang kita amati (Ida, 2016: 83).

\section{Hasil Dan Pembahasan}

\section{Tradisi Pedaq Api}

Pedaq api atau peraq api merupakan rangkaian upacara yang dilakukan sehubungan dengan adanya kelahiran anak (Suhardi, dkk. 2010: 31). Dalam bahasa Sasak, pedaq artinya padam dan api artinya api. Jadi, pedaq api diartikan sebagai pemadaman api. Akan tetapi, api yang dipadamkan merupakan api khusus, yaitu api penghangat yang biasanya begitu seorang ibu melahirkan dibuatkan perapian yang disebut dengan dapuh.

Dikutip dari https://doktersehat.com (19 September 2019) tentang setiap persalinan pasti mengeluarkan darah dan efek dari kekurangan darah ini adalah berkurangnya kadar hemoglobin (hb) darah yang berdampak pada tubuh. Akibatnya, kaki dan tangan menjadi dingin dan bahkan mati rasa. Oleh karenanya, pembuatan perapian untuk menghangatkan tubuh ibu pasca melahirkan menjadi begitu penting. Tidak hanya itu, fungsi perapian dapuh sebagai penghangat untuk ibu pasca melahirkan disesuaikan dengan kondisi ruang tempat tinggal masyarakat Sasak di masa lalu yang masih sederhana. Arsitektur rumah tinggal Sasak yang sederhana, salah satunya disebut dengan balé tajuk dimana struktur bangunannya bertiang sembilan dan terbuat dari bambu atau kayu bundar. Dindingnya terbuat dari anyaman bambu dan menggunakan lawang gongsor (pintu dorong) yang terbuat dari bambu. Atapnya pun menggunakan bahan jerami, re (alang), bahkan dari daun tebu atau gobok (daun kelapa) (Fathurrahman, 2016: 46). 


\section{e-ISSN 1412-9418 \\ Humanika Vol. 26 no 2 Copyright @2019 \\ Available online di http://ejournal.undip.ac.id/index.php/humanika}

Perapian dapuh terbuat dari kayu yang memiliki unsur wewangian, seperti galih waru (kayu garu), kayu cemara, dan daun lego. Perapian ini tersedia dalam sebuah tepaq (bak air yang terbuat dari tanah liat) yang diletakkan di dalam kamar ibu dan anak, berfungsi sebagai penghangat dan penghilang bau tidak sedap pasca melahirkan. Menjelang pelaksanaan pedaq api, api dapuh dikeluarkan untuk dipadamkan sekaligus dirangkai dengan pemberian nama pada anak. Kaitan antara pedaq api dengan pemadaman api dapuh adalah karena ibunya sudah bisa keluar, maka api di dalam kamarnya harus dipadamkan. Pemadaman api dapuh merupakan puncak akhir dari acara pedaq api. Peristiwa pemadaman api inilah yang memunculkan istilah pedaq api (Suhardi, dkk: 32). Sebelum acara pedaq api dilaksanakan, ibu dan anak ta kejames (dikeramas) dengan santan kelapa yang dicampur dengan kunyit sebagai simbol pembersihan total. Adapun bahan perlengkapannya terdiri dari moto siong (beras ketan yang disangrai), kerak (ketan yang diaduk dengan dengan gula merah atau gula kelapa) (Suhardi, dkk: 33).

Dalam Fathurrahman (2017: 152) dijelaskan perangkat acara dalam pedaq api disiapkan moto seyong (beras ketan yang disangrai), entèn- entèn (gula kelapa), daun bikan, sembeq (kunyahan sirih pinang),santan kelapa (untuk keramas ibu), gelang pelindung dan penanda, serta nama yang indah dan bermakna sebagai doa. Moto seyong dan entèn- entèn menggambarkan harapan agar anak kelak dapat menyebarkan rasa gurih dan manis dalam perilakunya. Kemudian, daun bikan diartikan agar hidupnya seloloq (sehat dan selamat) seperti daun bikan yang terus menjulur merambat segar dimana pun tumbuh. Sembeq adalah penanda agar anak dikenal oleh semua makhluk yang ada di sekitarnya bahwa ia sudah memiliki nama. Gelang pelindung atau penanda biasanya dibuat dengan benang hitam dan jeringo agar tidak diganggu makhluk halus.

Dalam beberapa acara ritual, seperti pedaq api dihadirkan suatu perangkat adat yang disebut dengan andang-andang. Rahmawati (2018) menjelaskan andang-andang merupakan simbol untuk mengawali suatu pekerjaan agar hasilnya sejalan dengan apa yang diniatkan. Terkait dengan niat, Rasulullah saw. menjelaskan bahwa sesungguhnya setiap amalan tergantung pada niatnya (HR. Bukhari, no. 1 dan Muslim, no. 1907). Oleh karenya, niat menjadi begitu penting dalam mengawali suatu kegiatan atau pekerjaan.

Komponen dari andang-andang terdiri dari beras, lekoq buaq (buah pinang dan daun sirih), telur, benang setokel atau benang katak (satu ikat), kepeng tepong atau kepeng bolong dan sembeq (kunyahan buah pinang dan daun sirih) (Fathurrahman, 2017: 146). Komponen ini merupakan simbol komunikasi dengan lingkungan semesta yang menunjukkan sikap memelihara harmoni (Mamiq Agus Fathurrahman, wawancara 15 Februari 2019).

Pelaksanaan pedaq api biasanya dilakukan di serambi, tepatnya di tirisan (cucuran) atap rumah yang disebut bebontot. Pedaq api dilakukan oleh belian (dukun beranak). Mulamula api dipadamkan dengan percikan daun bunut (daun beringin) dan tandan buaq bikan (batang buah bikan) yang diletakkan di atas tepaq. Bayi dan ibu yang sudah dikeramas dan dibersihkan dengan air sampai bersih disebut dengan masor. Selanjutnya, bayi ta eyok (diayak) dengan cara di ayun-ayun di atas bara api yang sudah dipadamkan. Waktu pelaksanaannya setelah petoq poset (putusnya tali pusar). Acara pedaq api dilaksanakan 
pada waktu nyepek peken (saat puncak keramaian pasar) antara pukul 09.00-10.00 pagi (Suhardi, dkk: 34). Setelah seluruh rangkain acara tersebut selesai, kemudian dilanjutkan dengan pemberian nama pada anak bayi. Nama yang disiapkan ditulis dalam kertas dan digenggamkan pada kedua tangan bayi. Apabila salah satu dari nama yang digenggam erat, berarti nama tersebutlah yang dipilih sendiri oleh bayi. Nama yang terpilih diletakkan di atas sèmbèq dan selanjutnya belian mencolekkan sèmbèq di kening bayi sambil menyebut namanya (Suhardi, dkk. 2010: 31-34).

Pada penyebutan nama ini sesungguhnya belian, Kiai atau orang yang dituakan berbicara kepada bayi untuk mengingatkan perjanjiannya dihadapan Allah SWT, diakhiri dengan pembacaan dua kalimat syahadat. Kiai memberikan nama dengan kalimat tertentu, misalnya "Kusembeq side baingku/anakku aran .... (sebut namanya) adeqde tao jauk aran jari kelampan. Bismillahirrahmaanirrahiim ...." (Saya sembeq engkau cucuku/ anakku dengan nama ..., semoga engkau bisa membawa nama menjadi perjalanan hidupmu). Kemudian, Kiai menggoreskan sembeq di kening bayi, mengenggamkan nama dan memasangkan gelang penanda atau gelang pelindung. Setelah semuanya selesai, Kiai memimpin doa dan selanjutnya menyantap moto seyong dan gula kelapa (Fathurrahman, 2017: 153).

Tradisi Pedaq Api' 'Pedaq Api' sebagai Keselamatan

Pedaq api yang dilaksanakan setelah kelahiran anak dan dilengkapi dengan perlengkapanperlengkapan tertentu menghasilkan konsep mental tentang upacara selamatan sebagai bentuk ucapan syukur kepada Tuhan Yang Mahakuasa. Makna simbolik tradisi pedaq api akan diuaraikan dalam tabel berikut.

Tabel. 1: Makna simbolik tradisi pedaq api

\begin{tabular}{ll}
\hline \multicolumn{1}{c}{ Penanda } & \multicolumn{1}{c}{ Petanda } \\
\hline Pedaq api & Upacara selamatan sebagai bentuk ucapan syukur kepada Tuhan \\
& Yang Mahakuasa \\
\hline Terlepasnya tali pusat & Kesiapan untuk menghadapi dunia baru, dalam menjalani \\
& kehidupan harus menjadi pribadi yang mandiri \\
\hline Tali pusat & $\begin{array}{l}\text { Adanya ujian dan cobaan yang akan dilalui seseorang dalam } \\
\text { kehidupannya, maka dari itu sebagai saudara harus saling } \\
\text { melindungi }\end{array}$ \\
\hline Air ketuban & Menunjukkan jalan keluar bagi bayi saat di dalam rahim dan \\
& saat ajal tiba sampai pintu surga terbuka \\
\hline Darah & Pelindung dari terik matahari dan dari serangan senjata tajam \\
\hline Adik-kakak & Saudara kembar yang melindungi di dunia rahim dan dunia alam \\
& kehidupan \\
\hline Bndang-andang & Simbol komunakasi dengan sesama pengkosmos yang ada di \\
& $\begin{array}{l}\text { alam jagat ini, melalui penyerahan diri kepada Tuhan Yang } \\
\text { mahakuasa-Si Epeyang Kula- Nenek Kaji Saq Kuasa-Allah Ta'ala }\end{array}$ \\
\hline Telur & Kesediaan untuk berbagi supaya memperoleh kedamian dan \\
& kemakmuran, semakin terpenuhinya kebutuhan pokok maka \\
& semakin berkurang tingkat penderitaan (kelaparan)
\end{tabular}




\begin{tabular}{ll}
\hline Kepeng bolong (uang logam) & $\begin{array}{l}\text { Setiap makhluk yang berasal dari alam (tanah) dalam perjalanan } \\
\text { hidupnya akan kembali pada alam (tanah) }\end{array}$ \\
\hline Benang katak (benang mentah) & $\begin{array}{l}\text { Kesatuan dalam menjunjung tinggi nilai-nilai persaudaraan } \\
\text { sesama makhluk sosial. }\end{array}$ \\
\hline Daun sirih dan buah pinang & $\begin{array}{l}\text { Percampuran antara sperma dan ovum, ayah dan ibu yang } \\
\text { melahirkan kehidupan manusia }\end{array}$ \\
\hline Sèmbèq & Prosesi penyatuan diri dengan Tuhan \\
\hline Moto seyong dan entèn- entèn & Keserhanaan dalam bersyukur kepada Tuhan Yang Mahakuasa \\
\hline Santan & $\begin{array}{l}\text { Kebersihan untuk ibu karena selama melahirkan sampai } \\
\text { menjelang pedaq api belum dikeramas }\end{array}$ \\
\hline Daun bikan & $\begin{array}{l}\text { Sejauh apapun dan sehebat apapun seseorang pasti memiliki } \\
\text { dasar yang menjadi asal muasalnya tumbuh dan berkembang }\end{array}$ \\
\hline Air & $\begin{array}{l}\text { Unsur yang ada di dalam tubuh manusia yang menjadi sumber } \\
\text { kehidupan }\end{array}$ \\
\hline Api & $\begin{array}{l}\text { Unsur amarah dan hawa nafsu di dalam diri manusia yang harus } \\
\text { dipadamkan }\end{array}$ \\
\hline Nama & $\begin{array}{l}\text { Manusia harus bisa membawa nama menjadi perjalanan } \\
\text { hidupnya }\end{array}$ \\
\hline
\end{tabular}

Pedaq api ditandai dengan terputusnya tali pusar yang biasanya berlangsung selama tujuh sampai sembilan hari usia anak (Fathurrahman, 2017: 151). Putusnya tali pusar dalam kosmologi Sasak, putusnya tali pusar diartikan sebagai terlepasnya secara total hubungan antara anak dengan rahim ibunya. Hal ini berarti bahwa anak sudah bisa berinteraksi dengan lingkungannya, maka dari dari itu dia diberikan nama sebagai identitas pengenalnya. Ini menjadi tanda kesiapan anak untuk menghadapi alam lingkungan yang mendefinisikan kemandirian.

Hubungan tali pusar dengan tradisi pemberian nama dalam pedaq api dikaitkan dengan empat saudara kembar anak ketika lahir, yaitu air ketuban, darah, tali pusat (plasenta), dan ari-ari yang disebut oleh orang Sasak sebagai Adik-kakak. Keempat saudara kembar bayi ini diinterpretasikan sebagai unsur yang melindunginya sejak di dalam rahim sampai kembali kepada Tuhannya.

Pertama, air ketuban diartikan sebagai penunjuk jalan saat ajal tiba sampai pintu surga terbuka. Kedua, darah dalam konteks pedaq api dimaknai sebagai unsur yang menyebabkan anak dapat leluasa bergerak di dalam rahim. Darah didefinisikan sebagai pelindung, setelah di dunia berperan sebagai pelindung anak dari terik matahari dan dari serangan senjata tajam. Ketiga, tali pusat. Simbol tali pusat (plasenta) menjadi saluran makanan dalam rahim ibu dimaknai sebagai pelindung seseorang di dunia dari gangguan setan. Artinya, adanya ujian dan cobaan yang akan dilalui seseorang dalam kehidupannya. Keempat, adik-kakak (ari-ari) diartika sebagai pelindung bayi di dalam rahim dan di dunia dapat melindunginya dari bala (Fathurrahman, 2017: 149).

\section{Makna 'Andang-Andang' sebagai Simbol Komunikasi dengan Alam}

Tradisi pedaq api dilengkapi dengan perangkat adat yang memiliki makna simbolis, dimana simbol utama yang digunakan adalah andang-andang sebagai simbol komunikasi yang 


\section{e-ISSN 1412-9418 \\ Humanika Vol. 26 no 2 Copyright @2019 \\ Available online di http://ejournal.undip.ac.id/index.php/humanika}

terdiri dari beras, telur, kepeng bolong (uang logam), benang katak (benang mentah), telur, daun sirih, kapur sirih dan buah pinang. Andang-andang dimaknai simbol komunikasi dengan lingkungan semesta yang menunjukkan sikap memelihara harmoni.

Komponen-komponen dalam andang-andang memiliki juga makna tersendiri. Beras bermakna kesediaan berbagi sebagai wujud syukur atas rizki yang dianugerahkan oleh Allah SWT. Telur yang digunakan dalam andang-andang adalah telur ayam kampung. Telur dimaknai sebagai keberadaan makhluk yang hadir ke dunia melalui proses telur/menetas. Simbol telur menjadi tanda kehadiran sebagi regenerasi keberlangsungan hidup manusia.

Simbol daun sirih, kapur sirih, dan buah pinang yang dijadikan sebagai sèmbèq, yaitu tanda bahwa anak sudah diberikan nama. Dalam konteks tradisi peda api diartikan sebagai simbol kejadian manusia. Tanda kejadian manusia menjadi mitos yang mendefinisikan percampuran antara sperma dan ovum, ayah dan ibu yang melahirkan kehidupan manusia. Buah pinang mewakili keberadaan makhluk yang tumbuh.

Simbol kepeng bolong (uang logam) dimaknai sebagai keterwakilan unsur mineral dalam alam yang harus dikembalikan ke alam. Hal ini didefinisikan bahwa makhluk yang berasal dari alam (tanah) dalam perjalanan hidupnya akan kembali pada alam (tanah). Simbol benang katak (benang mentah) yang digunakan dalam acara pedaq api adalah jenis tali sipat. Benang ini diartikan sebagai kesediaan untuk menjalin silaturrahmi dengan konsep saling menjaga dan saling mengikat.

\section{Tradisi 'Pedaq ap'i sebagai Representasi Perjalanan Hidup}

Simbol yang digunakan dalam tradisi pedaq api selain andang-andang adalah moto seyong (makanan sederhana yang dibuat dari beras ketan yang disangrai), entèn- entèn, santan (untuk keramas ibu), daun bikan, dan sèmbèq (kunyahan daun sirih, kapur sirih, dan buah pinang), air dan api (perapian). Moto seyong merupakan makanan yang terbuat dari beras ketan yang disangrai. Makanan ini merupakan makanan sederhana yang khusus disajikan pada acara pedaq api. Moto seyong sebagai makanan yang sederhana diartikan bahwa bersyukur kepada Tuhan Yang Mahakuasa dilakukan dengan carasederhana. Di samping itu, moto seyong dan entèn- entèn menyiratkan harapan kepada anak supaya kehidupannya baik-baik saja, sebagai mitos dapat menyebarkan rasa gurih dan manis dalam setiap perilakunya, disegani, serta disenangi oleh masyarakat (Fathurrahman, 2017: 152).

Daun bikan merupakan tumbuhan menjalar yang diasosiasikan dengan perjalanan hidup manusia. Tumbuhan ini sebagai representasi bahwa kehidupan anak akan terus menjalar, terus hidup, dan terus mengembara kemana-mana, serta terus menjulur merambat segar dimanapun tumbuh (Fathurrahman, 2017: 152). Sèmbèq merupakan kunyahan daun sirih, kapur sirih, dan buah pinang yang dicolekan pada kening anak sebagai penanda agar dikenal oleh semua makhluk yang ada di sekitarnya. Daun sirih dan buah pinang disebut oleh orang Lombok sebagai lekok buaq yang merupakan satu-satunya tumbuhan ketika disatukan, akan berubah warna menjadi merah yang menyerupai warna darah, sehingga inilah yang dipilih oleh masyarakat Sasak sebagai harapannya. Secara 


\section{e-ISSN 1412-9418 \\ Humanika Vol. 26 no 2 Copyright @2019 \\ Available online di http://ejournal.undip.ac.id/index.php/humanika}

hakekat, mereka ingin menyatu dengan Allah Ta'ale (Tuhan). Oleh karena itu, simbol dari lekok buaq ini adalah prosesi penyatuan diri dengan Tuhan.

Api dan air (air, tanah, api, udara) sebagai sumber kehidupan menjadi simbol-simbol antropologis yang dilatari dengan pemahaman filosofis atau tasauf. Empat unsur tanah, air, api, dan udara merupakan unsur kehidupan, dimana api menjelaskan bahwa di dalam diri manusia terdapat nafsu. Kemudian, unsur tanah menjelaskan bahwa pada dasarnya manusia berasal dari tanah, dan angin merupakan representasi unsur ruh karena unsur manusia adalah unsur ruh, serta air sebagai sumber kehidupan karena dalam tubuh manusia rata-rata tersusun $75 \%$ air dan otak tersusun atas $85 \%$ air (Briawan, dkk. 2011: 36). Terkait hal ini, Sattar (2010: 10) juga menjelaskan bahwa material asal yang empat, tanah, air, api, dan udara, sebagai unsur material qadîm sebagai realisasi unsur kehidupan.

\section{Simpulan}

Pedaq api merupakan ritual yang bersifat sakral karena didasari oleh pemikiran-pemikiran filosofis tasauf, dimana tanda-tanda simbolik yang ada merepresentasikan perjalanan hidup manusia. Akan tetapi, tidak banyak yang mengetahui hal ini karena melihat suatu fenomena budaya dari apa yang tampak secara visual tanpa mengetahui esensi dari suatu realitas. Dalam ritual pedaq api diselipkan harapan-harapan dan doa untuk anak supaya hidupnya selalu dinaungi oleh kebaikan-kebaikan. Untuk mencapinya, manusia tidak terlepas dari unsur-unsur yang ada dalam diri sebagai unsur kehidupannya, agar mengetahui bagaimana esensinya di alam dunia bahwa dirinya dan apapun yang ada di alam ini merupakan milik Tuhan yang pada waktu yang sudah ditentukan akan kembali pada-Nya.

Adapun eksistensi sufisme yang direpresentasikan melalui simbol-simbol kebudayaan dalam tradisi pedaq api dibagi menjadi tiga bagian. Pertama, tradisi pedaq api merupakan suatu bentuk ungkapan syukur yang dimaknai sebagai keselamatan. Kedua, tradisi pedaq api sebagai perantara untuk mengingatkan perjanjian anak dengan Tuhannya. Pada dasarnya keseluruhan peradaban manusia merupakan upaya untuk memelihara keseimbangan kosmologis. Upaya ini diekspresikan dengan ritual-ritual antropolgis sebagai simbol komunikasi dengan alam. Ketiga, tradisi pedaq api sebagai representasi dari perjalanan hidup manusia dari awal kejadian sampai kematian.

\section{Referensi}

Ansori, Zakaria. (2018). Tradisi Peraq Api dalam Dinamika Perubahan Sosial Pada Masyarakat Kawo. Jurnal Schemata, Vol. 7(1), 61-75.

Briawan, Dodik., Sedayu, T.S., \& Ekayanti, Ikeu. (2011). Kebiasaan Minum dan Asupan Cairan Remaja di Perkotaan. Jurnal Gizi Klinik Indonesia, Vol. 8(1), 36-41.

Fathurrahman, L.A. (2017). Kosmologi Masyarakat Sasak: Risalah Inen Paer. Mataram: Penerbit Genius.

. (2016). Membaca Arsitektur Sasak. Mataram: Genius.

https://doktersehat.com/perdarahan-pasca-persalinan/ (diakses 19-09- 2019).

Ida, Rachmah. (2014). Metode Penelitian: Studi Media dan Kajian Budaya. Jakarta: Prenadamedia Group. 
Maryam, Siti. (2018). Eksistensi Sufisme Sasak dalam Novel Sanggarguri dan Perannya dalam Kehidupan Masyarakat di Pulau Lombok. Jurnal Genta Bahtera, Vol. 4(1), 33-48.

Pitana, Titis Srimuda. (2014). Teori Sosial Kritis: Metode dan Aplikasinya. Purwokerto: STAIN Press.

Rahmawati, Ika Sri., Murahim., \& Qodri, Muh. Syahrul. (2018). "Makna Andang-Andang Pada Upacara Ngandang Rowot Sasak di Dusun Ende Lombok Tengah: Kajian Semiotika Peirce". http://eprints.unram.ac.id/id/eprint/8021 (07 Juli 2019).

Rahmawati, R., Nurhadi, Z.F., \& Suseno, N.S. (2017). Makna Simbolik Tradisi Rebo Kasan. Jurnal Penelitian Komunikasi, 20 (1), 61-74.

Ratna, Kutha. (2016). Metodologi Penelitian: Kajian Budaya dan IImu Sosial Humaniora Pada Umumnya. Yogyakarta: Pustaka Pelajar.

Sattar, A. (2010). Filsafat Islam: Antara Duplikasi dan Kreasi. Jurnal Ulumuna, XIV, 1-20.

Suhardi., Yasri, H., \& Mursip. (2010). "Upacara Daur Hidup Suku Sasak". Mataram: Pustaka Widya.

Suhupawati. (2017) Upacara Adat Kelahiran Sebagai Nilai Sosial Budaya Pada Masyarakat Suku Sasak Desa Pengadangan. Jurnal Fajar Historia, Vol. 1(1), 55-65.

Tausikal, Muhammad Abduh. (2017). “Hadits Arbain \#01: Setiap Amalan Tergantung pada Niat". https://rumaysho.com/16311-hadits-arbain-01-setiap-amalan-tergantungpada-niat.html (20 September 2019).

Zulkarnain, Hardi. (2019). “Proses Ritual Pedak Api Di Desa Merembu Kecamatan Labuapi Ditinjau Dari Nilai-Nilai Pancasila". http://fkipunram.rf.gd/ifkip3.php?nim=E1B114015\&i=1(21 Juni 2019). 